\title{
Does prevention for Alzheimer's disease exist?
}

\author{
Sonia Maria Dozzi Brucki
}

\begin{abstract}
The prevention of Alzheimer's disease is a growing public health concern amidst an ageing population. Meanwhile, there is no effective or curative treatment available where prevention could greatly reduce health costs. This review was based on reports of potential preventive factors, including modifiable lifestyle factors, as well as preventive pharmacological strategies. Although the present review was not systematic, the reports selected from PubMed using "Alzheimer's disease" and "prevention" as key-words, allow us to affirm that pursuing a healthy lifestyle; physical, cognitive, leisure activities; good social engagement; a high consumption of fish, low consumption of dietary fat and moderate consumption of wine, and control of vascular risk factors appear to be potential factors for delaying dementia.
\end{abstract}

Key words: Alzheimer's disease, prevention, physical exercise, statins, cholinesterase inhibitors, nutrition.

\begin{abstract}
A prevenção da doença de Alzheimer existe?
Resumo - A prevenção da doença de Alzheimer é um problema de saúde pública, enquanto a população está envelhecendo. Por enquanto, não há tratamento efetivo ou curativo e prevenção poderia evitar grandes custos financeiros. Esta revisão foi baseada em estudos sobre potenciais fatores preventivos, incluindo fatores modificáveis de estilo de vida, bem como estratégias farmacológicas preventivas. Embora esta revisão não seja sistemática, estudos selecionados do PubMed, com palavras-chave "Alzheimer's disease" e " prevention", permitem afirmar que ter um estilo de vida saudável, atividades físicas, cognitivas e de lazer; bom engajamento social; aumento no consumo de peixes, redução no consumo de gorduras consumo meoderado de vinho; controle dos fatores de risco vasculares parecem ter vantagens potenciais em retardar a demência.

Palavras-chave: doença de Alzheimer, prevenção, exercício físico, estatinas, inibidores de colinesterases, nutrição.
\end{abstract}

Delaying the onset of dementia syndrome is a serious health issue which has financial, economic, and social repercussions. The global prevalence of dementia was estimated at 24.3 million in 2001, ${ }^{1}$ while that of Alzheimer's disease (AD) was 26.55 million in 2006 , and is predicted to rise to 106.2 millions by 2050 . Retarding the clinical picture of dementia by 12 months represents a huge reduction of around 9.2 million cases.

In Brazil and Latin America, the prevalence of dementia in subjects aged 65 years or older is $7.2 \%$ and $15.7 \%$ among non-illiterates and illiterates, respectively. ${ }^{2}$

Some risk factors for developing AD are well established: age, family history, female gender (not for all surveys), low educational level, depressive symptoms, traumatic brain injury, the presence of E4 allele of APOE, hypercholesterolemia, smoking, sedentary life-style, and mild cognitive impairment.
Studies have established some factors associated to maintenance of good cognitive aging. In a longitudinal follow-up of a cohort of elderly females over a 15 -year period, Barnes et al. observed that persons who remained cognitively stable presented a lesser number of clinical co morbidities (such as arterial hypertension and diabetes), less complaints regarding difficulties in activities of daily living, and greater social integration. ${ }^{3}$ More recently, in an eight year follow-up study of 3075 elders aged between 70 and 79 years in 1997, 30\% of the sample had no cognitive decline, while multivariate analysis found the following baseline variables to be associated with being a maintainer: lower age, white race, higher educational and literacy levels, weekly moderate to vigorous exercise and non-smoker status. ${ }^{4}$

Autopsy series of elderly subjects with normal cognitive function have found high burdens of pathological lesions associated with $\mathrm{AD}$, for which several explanations have

MD, PhD, Neurologist from the Cognitive and Behavioral Neurology Group (University of São Paulo); Psychobiology Department (Federal University of São Paulo); Hospital Santa Marcelina, São Paulo, SP, Brazil.

Sonia Maria Dozzi Brucki - Rua Rio Grande 180/61 - 04018-000 São Paulo SP - Brazil. E-mail: sbrucki@uol.com.br

Disclosure: The authors report no conflicts of interest.

Received July 8, 2009. Accepted in final form August 19, 2009. 
been proposed. One explanation points to compensatory mechanisms of brain reserve. In the study by Erten-Lyons et al., some factors associated with resistance to dementia despite high $\mathrm{AD}$ pathology were determined by comparing individuals with high burden pathology and normal cognition against patients with $\mathrm{AD}$ presenting an equivalent burden of lesions. In multiple regression analysis, hippocampal and total brain volumes were significantly larger in the group with normal cognitive functions. The authors proposed three possible explanations: larger brain volumes may indicate a greater preexisting brain reserve; the cognitively intact group may have had other forms of compensation or protection from the pathologic processes; and, the brain volume loss in the $\mathrm{AD}$ group may not have been directly caused by neurofibrillary tangles and senile plaques. The underlying protective process remains unknown. ${ }^{5}$

The aim of this report was to describe some results of interventions intended to prevent conversion from healthy or mild cognitive impairment subjects into AD. Some interventions can modify outcome in terms of developing dementia for a certain period of time. Epidemiologic research has revealed various possible preventive factors, including modifiable lifestyle factors and pharmacological strategies. Our aim was to present the results of several clinical trials demonstrating efficacy in delaying progression to dementia. Only results from recent longitudinal studies, randomized controlled trials, and reviews assessing the prevention of $\mathrm{AD}$, conversion of $\mathrm{MCI}$ to dementia will be described, where only PubMed articles with full-text in the English language published from 1998 to 2009 (June) using Alzheimer's Disease and prevention as key-words were selected.

\section{Non-pharmacological interventions}

\section{Cognitive, leisure, and physical activities}

Some studies have found a positive association between leisure activities and lower risk for developing $\mathrm{AD}$ or dementia in general. ${ }^{6,7}$ Verghese et al. have attempted to control for possible confounding factors such as the preclinical stage of dementia (which prevents elderly from performing leisure and cognitive activities). They evaluated community-dwelling subjects aged 75 to 85 years old during a period spanning from 1980 to 2001. Subjects were analyzed regarding participation in cognitive activities (reading books or newspapers, writing for pleasure, doing crossword puzzles, playing board games or cards, participating in group discussions, and playing musical instruments) and for physical activities (playing tennis or golf, swimming, bicycling, dancing, participating in group exercises, playing team games, walking for exercise, climbing more than two flights of stairs, doing housework, or babysitting). At the end of the follow-up (median time of 5.1 years),
124 subjects had developed dementia (AD, $\mathrm{n}=61$; vascular dementia, $\mathrm{n}=30$ ). Subjects who became demented tended to be older, had less schooling, and performed less cognitive activities (which reduce risk of $\mathrm{AD}$, vascular dementia and mixed dementia), but not physical activities (with the exception of dancing). Among cognitive activities, reading, playing board games, and playing musical instruments were associated with a lower risk of dementia. ${ }^{8}$ In a new analysis of this same sample performed to verify the influence of leisure or physical activity participation on risk of developing amnestic mild cognitive impairment (aMCI), the authors observed that cognitive activities were associated with lower risk of aMCI. ${ }^{9}$ In a study of twin pairs of male veterans (Duke Twin Study of Memory in Aging), cognitive activity reduced development of dementia in $26 \%$ (particularly among homozygotic pairs $-30 \%$ reduction). Physical activity however, played no modifying role. ${ }^{10}$ Social activity is associated with risk for $\mathrm{AD}$, with subjects that have low social engagement being more prone to developing dementia, while those exhibiting mid and late-life social activity were associated with greater cognitive and physical health. ${ }^{11-14}$ Cognitive activities are associated with greater and preserved cognitive reserve, that is, the capacity of the brain to cope with the pathology of dementia through structural or functional characteristics and networks, or alternative cognitive strategies that protect the subject until a certain threshold is reached.

More recently, in a 24-week randomized controlled clinical trial, physical activity was associated with a lower risk for developing MCI and dementia among adults with subjective memory impairment. The study was conducted at the Royal Perth Hospital (Australia) in volunteers aged 50 years or older, randomly assigned to an education program or to a 24-week home-based program of physical activity. There was a significant, albeit modest difference in cognitive performance among those undertaking the physical program, a difference which persisted over an 18month follow-up period. ${ }^{15}$ The literature on associations among physical activity, cognition, and risk for dementia is conflicting, but this latter study appears to demonstrate a clear positive effect.

In animal studies, physical activity stimulates angiogenesis, synaptogenesis, and neurogenesis. Rats performing treadmill running activity had more astrocytes and neuroblasts with proliferative ability in the subgranular zone of the dentate gyrus of the hippocampus, as well as an increased number of neurons in the transient stage that control rats. ${ }^{16}$ Physical exercise also decreases risk factors for vascular diseases, and can release hormonal factors that boost neuronal functions, reinforcing the theoretical basis of potential benefits. 


\section{Alcoholic beverages}

There is a large body of evidence suggesting that moderate alcohol consumption is associated with reduced risk of coronary heart disease, ischemic stroke and dementia. ${ }^{17-20}$ Nineteen longitudinal cohort studies compared relative risk factors for either cognitive decline or dementia in older moderate alcohol consumers versus abstainers/never drinkers. In these studies, approximately $54 \%$ of the risk factors were significantly lower in moderate consumers. In a Swedish study, women were followed for 34 years, and analysis was made verifying different types of beverages (wine, beer, and spirits). Wine was protective for dementia, and the association was strongest among women who consumed wine only, and among smokers. Notwithstanding, consumption of spirits at baseline was associated with slightly increased risk of dementia. ${ }^{21}$

Protective mechanisms involved in the association of alcohol consumption with decrease in risk of dementia and vascular alterations, include increase of HDL and decrease of LDL, resulting in lowering of risk due to cholesterol; reduction of insulin resistance and increase in insulin sensitivity; reduction of blood homocysteine; decrease of systemic arterial pressure; reduction in platelet aggregation and fibrinogen levels, with increased fibrinolysis; and reduction in inflammatory markers. Reduction of dementia is associated not only with lower vascular factors, but also with antioxidant polyphenols such as resveratrol. There appears to be an antagonist effect on NMDA receptors by alcohol, and anti-amyloidogenic activity by resveratrol. It has no effect on $\beta$ - e $\gamma$ - secretases, but instead promotes intracellular degradation of $\mathrm{A} \beta$ via a mechanism that involves the proteasome $\mathrm{e}^{20,22,23}$. Although mild to moderate consumption (one to two drinks, $<30 \mathrm{~g} / \mathrm{d}$ ) is associated with lower risk for cerebrovascular and cardiac diseases; intake of three or more drinks increases rate of ischemic and hemorrhagic stroke.

\section{Mediterranean diet}

The Mediterranean diet is characterized by high intake of fish, vegetables, legumes, fruit, cereal, and unsaturated fatty acids (olive oil); low intake of dairy products, meat, and saturated fatty acids, and moderate consumption of alcohol. Some studies have verified a protective factor of high Mediterranean diet adherence against MCI development (borderline reduction risk) and a reduced risk of $\mathrm{MCI}$ conversion to $\mathrm{AD} .^{24-26}$

\section{Pharmacological interventions Ginkgo Biloba}

Recently, a randomized double blind placebo controlled trial ( $G$ biloba $240 \mathrm{mg} / \mathrm{d}$ versus placebo) was published involving five centers in the USA, conducted between 2000 and 2008, with a median follow-up of 6.1 years. Subjects were evaluated every 6 months and 523 individuals developed dementia (246 from placebo group versus 277 from $G$ biloba group). Results have shown that Ginkgo Biloba provided no benefit in reducing $\mathrm{AD}$ development or conversion of $\mathrm{MCI}$ into $\mathrm{AD}^{27}$.

\section{Statins}

Four large cohort studies showed the same effect of reduced risk of incident AD with statin use. ${ }^{28-31}$ Some doubts existed over which type of statin was most linked to decreased incidence of dementia based on their lipophilicity. Lipophilic statins were thought to pass the blood-brain barrier (BBB) more efficiently than hydrophilic statins. Haag et al. evaluated the use of cholesterol-lowering drugs and divided them into three classes: lipophilic statins (simvastatin, atorvastatin, cerivastatin), hydrophilic statins (pravastatin, fluvastatin, rosuvastatin), and non-statin cholesterol lowering drugs (fibrates, bile acid binding resins or nicotinic acid and derivatives). Use of statins, despite their lipophilicity, but not use of non-statin cholesterol lowering drugs, was associated with a reduced risk of AD compared with never users. ${ }^{31}$ This protection was effective independent of APOE4 genotype status. These results seem to indicate that permeability of the BBB is not the main protection mechanism. Other mechanisms must be associated to reduced risk of dementia by statins: inhibition of cholesterol synthesis, endothelial functioning, atherosclerosis and oxidative stress reactions, inhibition of amyloid synthesis and reduction of neurofibrillary tangle burden. ${ }^{31}$

\section{Antihypertensive drugs}

There is relatively strong evidence that hypertension in midlife represents a risk factor for dementia or cognitive decline. Recently, a neuropathologic study reported that persons who were treated for hypertension in midlife were less demented clinically and had less AD pathology than both hypertensive patients who were not treated and nonhypertensive patients. ${ }^{32}$ The association of dementia with late-life blood pressure has yielded heterogeneous results. The effects of antihypertensive treatment in late life on risks of dementia are not uniform. It is known however, that arterial hypotension in late life can result in increased risk for cognitive impairment, through ischemia and hypoperfusion. A recent study has shown antihypertensive use to be associated with a significant reduction in dementia in subjects less than 75 years old. ${ }^{33}$

Some randomized controlled trials of antihypertensive medications have shown reductions in incident dementia. ${ }^{34-36}$ Doubts over response to specific classes of antihypertensive drugs remain. 


\section{Cholinesterase inhibitors}

The use of cholinesterase inhibitors (donepezil, rivastigmine, galantamine) is well established for $\mathrm{AD}$ treatment, with relative increase or preservation of cognitive scores and improvements in measures of global clinical impression observed in studies involving patients with mild to moderate and moderate to severe stages of dementia. Mild cognitive impairment (MCI) is a recognized risk factor for AD development, particularly in amnestic presentation. Some studies, majority of which produced negative results, have been conducted to determine reduction in conversion of $\mathrm{MCI}$ to $\mathrm{AD}$.

\section{Donepezil}

During a mean follow-up of three years, results showed no decrease in risk for conversion of $\mathrm{MCI}$ to $\mathrm{AD}$ upon use of donepezil compared to placebo, although a reduced risk for APOE4 carriers was identified. ${ }^{37}$ In a later sub-analysis of the same sample, a lessened benefit in conversion to dementia was observed among individuals with concomitant depression. ${ }^{38}$

In a randomized double blind placebo controlled clinical trial, with a follow-up of 48 weeks, a discrete improvement in scores on the modified ADAS-Cog (primary measure of efficacy) was found among MCI patients versus the placebo group. Nevertheless, no differences were observed in measures of global or functional impairments. A higher number of subjects in the active group abandoned treatment due to adverse events; ${ }^{38}$ a similar result was demonstrated by Salloway et al. ${ }^{39}$

\section{Rivastigmine}

The InDDEx study was a double blind, randomized, placebo-controlled trial of up 48 months which sought to investigate whether rivastigmine delayed progression to $\mathrm{AD}$ in patients with $\mathrm{MCI}$, and to assess possible benefits among cognitive functions in MCI patients. Subjects were assigned to a rivastigmine group $(\mathrm{n}=508)$ or placebo group $(\mathrm{n}=510)$. No significant difference in rates were found in either dementia or cognitive benefit, along with more adverse events in the active group. ${ }^{40}$

\section{Galantamine}

In two studies involving 2048 subjects who were allocated to placebo or active groups, galantamine failed to prevent the progression of MCI to dementia. These studies showed no significant changes in ADAS-Cog/MCI or ADCS/MCI scores at month 12 or month 24, irrespective of number of ApoE-4 alleles. Adverse events were more common in the galantamine group. ${ }^{41}$

Current evidence is insufficient to recommend the prescription of cholinesterase inhibitors for $\mathrm{MCI}$ or as a measure to delay development of dementia. Several points however should be emphasized: a significant percentage of subjects with MCI, spontaneously revert to normal cognition, and not all cases of MCI progress to dementia; amnestic $\mathrm{MCI}$ subjects are more prone to convert to $\mathrm{AD}$ than non-amnestic MCI; the instruments available probably lack the sensitivity to measure an effect of these types of drugs.

\section{Conclusions}

Although our review was not systematic, several conclusions can be drawn. Having a healthy lifestyle; physical, cognitive, leisure activities; good social engagement; high consumption of fish, low consumption of dietary fat and moderate consumption of wine; control of vascular risk factors, such as arterial hypertension, diabetes mellitus, dyslipidemias, and being a non-smoker seem to be potential advantages in delaying dementia. These factors are all modifiable in the lives of individuals, and can lead to improved quality of life for all. Other bio and genetic markers may prove useful for determining who could most benefit from these interventions, as well as other pharmacological interventions.

\section{References}

1. Ferri CP, Prince M, Brayne C, et al. Global prevalence of dementia: a Delphi consensus study. Lancet 2005;366:2112-2117.

2. Nitrini R, Bottino CMC, Albala C, et al. Prevalence of dementia in Latin America: a collaborative study of populationbased cohorts. Int Psychogeriatrics 2009;21:622-630.

3. Barnes DE, Cauley JA, Lui LY, et al. Women who maintain optimal cognitive function into old age. J Am Geriatr Soc 2007;55:259-264.

4. Yaffe K, Fiocco AJ, Vittinghoff E, et al. Predictors of maintaining cognitive function in older adults. The Health ABC Study. Neurology 2009;72:2029-2035.

5. Erten-Lyons D, Woltjer RL, Dodge H, et al. Factors associated with resistance to dementia despite high Alzheimer disease pathology. Neurology 2009;72:354-360.

6. Scarmeas N, Levy G, Tang MX, Manly J, Stern Y. Influence of leisure activity on the incidence of Alzheimer's disease. Neurology 2001;57:2236-2242.

7. Wilson RS, Mendes De Leon CF, Barnes LL, et al. Participation in cognitive stimulating activities and risk of incident Alzheimer's disease. JAMA 2002;287:742-748.

8. Verghese J, Lipton RB, Katz MJ, et al. Leisure activities and the risk of dementia in the elderly. N Engl J Med 2003;348:2508-2516.

9. Verghese J, LeValley A, Derby C, et al. Leisure activities and the risk of Amnestic Mild Cognitive Impairment in the elderly. Neurology 2006;66:821-827.

10. Carlson MC, Helms MJ, Steffens DC, Burke JR, Potter GG, Plassman BL. Midlife activity predicts risk of dementia in 
older male twin pairs. Alzheimer's \& Dementia 2008;4: 324-331.

11. Bennett DA, Schneider JA, Tang Y, Arnold SE, Wilson RS. The effect of social networks on the relation between Alzheimer's disease pathology and level of cognitive function in old people: a longitudinal cohort study. Lancet Neurol 2006;5:406-412.

12. Podewills LJ, Guallar E, Kuller LH, et al. Physical activity, APOE genotype, and dementia risk: findings from the Cardiovascular Health Cognition Study. Am J Epidemiol 2005;161:639-651.

13. Saczynski JS, Pfeifer LA, Masaki K et al. The effect of social engagement on incident dementia: the Honolulu-Asia Aging Study. Am J Epidemiol 2006;163:433-440.

14. Wang HX, Karp A, Winblad B, Fratiglioni L. Late-life engagement in social and leisure activities is associated with a decreased risk of dementia: a longitudinal study from the Kungsholmen project. Am J Epidemiol 2002;155:65-73.

15. Lautenschlager NT, Cox KL, Flicker L, et al. Effect of physical activity on cognitive function in older adults at risk for Alzheimer's disease. A randomized trial. JAMA 2008;300:1027-1037.

16. Uda M, Ishido M, Kami K, Musuhara M. Effects of chronic treadmill running on neurogenesis in the dentate gyrus of the hippocampus of adult rat. Brain Res 2006;1104:64-72.

17. Ruitenberg A, van Sweiten JC, Witteman JCM, et al. Alcohol consumption and risk of dementia: the Rotterdam study. Lancet 2002;359:281-286.

18. Mukamal KJ, Kuller LH, Fitzpatrick AL, et al. Prospective study of alcohol consumption and risk of dementia in older adults. JAMA 2003;289:1405-1413.

18. Espeland MA, Gu L, Masaki KH, et al. Association between reported alcohol intake and cognition: results from the Women's Health Initiative Memory Study. Am J Epidemiol 2005; 161:228-238.

19. Collins MA, Neafsey EJ, Mukamal KJ, et al. Alcohol in moderation, cardioprotection, and neuroprotection: epidemiological considerations and mechanistic studies. Alcohol Clin Exp Res 2009:33:206-219.

20. Mehlig K, Skoog I, Guo X, et al. Alcoholic beverages and incidence of dementia:34-year follow-up of the prospective population study of women in Göteborg. Am J Epidemiol 2008;167:684-691.

21. Marambaud P, Zhao H, Davies P. Resveratrol promotes clearance of Alzheimer's disease amyloid- $\beta$ peptides. J Biol Chem 2005;280:37377-37382.

22. Vingtdeux V, Dreses-Werringloer U, Zhao H, Davies P, Marambaud P. Therapeutic potential of resveratrol in Alzheimer's disease. BMC Neuroscience 2008;9(Suppl 2):S6.

23. Scarmeas N, Stern Y, Mayeux R, Luchsinger JA. Mediterranean diet, Alzheimer disease, and vascular mediation. Arch Neurol 2006;63:739-747.

24. Scarmeas N, Stern Y, Tang MX, Mayeux R, Luchsinger JA. Mediterranean diet and risk for Alzheimer's disease. Ann Neurol 2006;59:922-927.

25. Scarmeas N, Sterm Y, Mayeux R, Manly JJ, Schupf N,
Luchsinger JA. Mediterranean diet and Mild Cognitive Impairment. Arch Neurol 2009;66:216-225.

26. DeKosky ST, Williamson JD, Fitzpatrick AL, et al. Ginkgo Biloba for prevention of dementia: a randomized controlled trial. JAMA 2008;300:2253-2262.

27. Green RC, McNagny SE, Jayakumar P, et al. Statin use and the risk of Alzheimer's disease: the MIRAGE Study. Alzheimer's \& Dementia 2006:2:96-103.

28. Cramer C, Haan MN, Galea S, et al. Use of statin and incidence of dementia and cognitive impairment without dementia in a cohort study. Neurology 2008;71:344-350.

29. Sparks DL, Kryscio RJ, Sabbagh MN, et al. Reduced risk of incident $\mathrm{AD}$ with elective statin use in a clinical trial cohort. Curr Alzheimer Res 2008;5:416-421.

30. Haag MDM, Hofman A, Koudstaal PJ, Stricker BHC, Breteler MMB. Statins are associated with a reduced risk of Alzheimer disease regardless of lipophilicity. The Rotterdam Study. J Neurol Neurosurg Psychiatry 2009;80:13-17.

31. Hoffman LB, Schmeidler J, Lesser GT, et al. Less Alzheimer disease neuropathology in medicated hypertensive than nonhypertensive persons. Neurology 2009;72:1720-1726.

32. Haag MDM, Hofman A, Koudstaal PJ, Breteler MMB,Stricker BHC. Duration of antihypertensive drug use and risk of dementia: a prospective cohort study. Neurology 2009;72:1727-1734

33. Hanon O, Forette F. Treatment of hypertension and prevention of dementia. Alzheimer Dement J Alzheimer Assoc 2005;1:30-37.

34. Forette F, Seux ML, Staessen JA, et al. Prevention of dementia in randomised double-blind placebo-controlled Systolic Hypertension in Europe (Syst-Eur) trial. Lancet 1998;352:1347-1351.

35. Tzourio C, Anderson C, Chapman N, et al. Effects of blood pressure lowering with perindopril and indapamide therapy on dementia and cognitive decline in patients with cerebrovascular disease. Arch Intern Med 2003;163:1069-1075.

36. Petersen RC, Thomas RG, Grundman M, et al. Vitamin E and donepezil for the treatment of mild cognitive impairment: Alzheimer's Disease Cooperative Study Group. N Engl J Med 2005;352:2379-2388

37. Lu PH, Edland SD, Teng E, et al. Donepezil delays progression to $\mathrm{AD}$ in $\mathrm{MCI}$ subjects with depressive symptoms. Neurology 2009;72:2115-2121.

38. Doody RS, Ferris SH, Salloway S, et al. Donepezil treatment of patients with MCI - A 48-week randomized, placebo-controlled trial. Neurology 2009;72:1555-1561.

39. Salloway S, Ferris S, Kluger A, et al. Efficacy of donepezil in mild cognitive impairment. A randomized placebo-controlled trial. Neurology 2004;63:651-657.

40. Feldman HF, Ferris S, Winblad B, et al. Effect of rivastigmine on delay to diagnosis of Alzheimer's disease from mild cognitive impairment: the InDDEx study. Lancet Neurol 2007;6:501-512.

41. Winblad B, Gauthier S, Scinto L, et al. Safety and efficacy of galantamine in subjects with mild cognitive impairment. Neurology 2008;70:2024-2035. 